\title{
Effects of Calci Soya Balance and Vitagnus on Menopausal Symptoms
}

\author{
Shahnaz Golian Tehrani ${ }^{1,}$; Shahin Bazzazian ${ }^{1}$; Azam Bakhtiarian ${ }^{2}$; Maryam Ghobadzadeh ${ }^{1}$ \\ ${ }^{1}$ School of Nursing and Midwifery, Tehran University of Medical Sciences, Tehran, IR Iran \\ ${ }^{2}$ Department of Pharmacology, School of Medicine, Tehran University of Medical Sciences, Tehran, IR Iran \\ ${ }^{*}$ Corresponding Author: Shahnaz Golian Tehrani, School of Nursing and Midwifery, Tehran University of Medical Sciences, P. O. Box: 1419733171, Tehran, IR Iran. Tel: +98-2166927171, \\ E-mail:golian@tums.ac.ir
}

Received: August 27, 2013; Revised: April 27, 2014; Accepted: July 7, 2014

\begin{abstract}
Background: Menopause is a period of women's lives with changes and symptoms that affect their work, sleep and quality of life. Therefore, it is important to overcome these symptoms.

Objectives: The aim of the present study was to compare the effects of Calci soya balance and Vitagnus on menopausal symptoms.

Patients and Methods: This double-blinded controlled trial study was performed in public health centers of Tehran University of Medical Sciences (2011-2012). Seventy postmenopausal women with menopausal symptoms were randomly divided into two groups of treatments with Vitagnus and Calci soya balance. Data were collected using interviews, answering Cooperman's index questionnaires before four and eight weeks after the treatment. Descriptive and analytic statistics were used for analyzing the data.

Results: In both groups, Wilcoxon test showed a significant decrease in the mean of Cooperman's menopausal index as well as after four and eight weeks of treatment $(\mathrm{P}=0.000)$.Mann-Whitney test did not show any significant differences between the two groups, before and after four and eight weeks of treatment.

Conclusions: The results showed that both Vitagnus and Calci soya balance were effective on reduction of menopausal symptoms to a similar extent and medical community can administer each of these two drugs based on patients' conditions and costs.
\end{abstract}

Keywords:Vitagnus; Soybeans; Menopause; Clinical Trial; Tehran

\section{Background}

Menopause is a transitional period in women's lives, in which estrogen and progesterone loss, menstrual disorders, and finally the end of ovulation menorrhea occur. Normally, menopause occurs between the ages of 45-55 and completes when period does not occur for one year (1). Menopause is associated with many symptoms, most of which are due to estrogen reduction. Some of these symptoms include hot flushing, night sweats, redness of skin, sleep problems, increased heart disease risk, mood disturbances such as irritability, depression and anxiety, decreased libido, and increased bone loss, which can lead to osteoporosis (2). The most common symptom is hot flushing and about $75 \%$ of women experience it. Its frequency of incidence varies between a few times in a month to several times a day and can even disturb sleeping (3). About $20 \%$ of women complain of severe hot flushing, which can be associated with fatigue, nervousness, anxiety, irritability, depression, and memory loss (4). Nowadays, with the increase in life expectancy, women spend almost one-third of their lives undergoing menopause (5). It is important to treat these symptoms, because the ability to work, social life and daily activities are directly related to a person's health status. One of the methods for treatment of menopausal symptoms is hormone therapy; but in some cases it increases the risk of heart attack, stroke, bladder diseases and breast cancer (6). Regarding the prevalence variation of hot flushes among different societies, it seems to be related to difference in diet, especially intake of foods containing phytoestrogens (7). Therefore, tendency to consume phytoestrogens in Japanese and Asian communities have had a dramatic impact on reducing hot flush and night sweating in postmenopausal women, compared with western societies (8). Phytoestrogens are naturally found in some plants, including grains, soy, hops, red clover, flaxseed, Vitex agnus-castus, and alfalfa (9). Vitex agnus-castus is a plant found in Asia and Mediterranean countries. This plant in forms of tablets and drops is available in Iranian pharmacies. Vitagnus is a drop made from the dried ripe fruit of Vitex agnus-castus. This drug is taken to treat menstrual disorders, menopause symptoms, fibroids, fibrocystic breast disease, infertility, and acne in women. The drug mechanism of action is partially unknown, but seems to decrease follicle stimulating hormone (FSH) and increase luteinising hormone (LH) through an impact on the hypothalamic-pituitary axis (10). In addition to Vitex agnus-castus, some other plants that contain phytoestrogens may also alleviate menopause symptoms. One of these plants

Copyright ( 2014, Iranian Red Crescent Medical Journal; Published by Kowsar. This is an open-access article distributed under the terms of the Creative Commons Attribution-NonCommercial 4.0 International License (http://creativecommons.org/licenses/by-nc/4.0/) which permits copy and redistribute the material just in noncommercial usages, provided the original work is properly cited. 
is soy, a vegetable protein source with no cholesterol and only a small amount of saturated fatty acids. Soy isoflavones are a group of compounds with estrogenic properties, classified under phytoestrogens. Several studies have shown that soy consumption may have beneficial effects for women, particularly postmenopausal individuals (11, 12). Ebrahimi and Yecta studied the effects of soy protein on menopausal symptoms in Urmia city, Iran. This quasiexperimental, longitudinal, double-blinded, case-control study was conducted to determine the effects of soy protein on menopausal symptoms in 80 postmenopausal women who were randomly divided into two groups, case and control. The case group received 20 grams of soy protein daily, while the control group received placebo. Menopause symptoms were measured based on Cooperman's index before the intervention, and after weeks four, eight, and 12. Results showed that soy protein at the end of weeks four, eight and 12 could diminish the severity of menopausal symptoms. Regarding the beneficial effects of soy as well as the adverse effects of hormones and synthetic drugs, it seems that soy and its preparations have the potential to be one of the simple, safe and low cost regimens to relieve menopausal symptoms (13). In an experiment conducted by Kazemian et al. in Isfahan city, Iran, effects of Vitagnus and Pasipay on menopausal symptoms were investigated. In that prospective doubleblinded clinical trial, 81 postmenopausal women referred to health centers of the city were selected. Using a simple sampling method, they were divided randomly into three equal groups: Vitagnus, Pasipay, and placebo. Data were collected by interview, individual characteristic questionnaire, and Cooperman's flushing severity questionnaire, completed before and after the treatment in three phases. Results showed that there was a significant difference in severity of symptoms among the three groups after the treatment using Kruskal-Wallis. Mann-Whitney test showed significant differences between placebo and Vitagnus groups and also for Pasipay compared with the placebo group. Kruskal-Wallis did not detect any significant difference in duration and frequency of hot flushing between the three groups. The results showed that Vitagnus and Pasipay were effective in diminution of menopausal flushing intensity and can be used as an alternative treatment for reducing the intensity of symptoms for women who cannot use hormone replacement therapy (14). In a systematic review and meta-analysis study conducted by Bolanos et al. in 2010, the effects of soy isoflavones and placebo on menopausal symptoms were evaluated. They surveyed 19 experimental and a control group and lasted for 12 weeks. Although the results tended to report soy as an effective agent, proof of this hypothesis needs further investigations (15). The listed experiments were motivations for research in this field at the present study. One of the soy-containing compounds that are available in Iranian markets is Calci soya balance, which is used as a calcium and soy containing supplement to decrease menopausal symptoms.

\section{Objectives}

The purpose of this study was to compare the effects of Calci soya balance and Vitagnus on menopausal symptoms (hot flushing, paresthesia, insomnia, nervousness, feelings of severe sadness, vertigo, weakness, arthralgia, myalgia, headache, palpitation, and tingling of the limbs).

\section{Patients and Methods}

This study was a randomized double-blinded controlled trial, performed on 70 postmenopausal women selected among patients referring for Pop smear test in five public health centers of Tehran University of Medical Sciences within nine months from September 2011 to June 2012, in Tehran, Iran. Following ethical approval from the Ethics Committee of Tehran University of Medical Sciences and registering the research at the clinical trials website by ID IRCT201102215878N1, the sampling started. The sample size formula per group was as follows:

$$
2\left(Z_{1-\frac{\alpha}{2}}+Z_{1-\beta}\right)^{2} \frac{\left(\partial_{1}+\frac{\partial_{2}}{2}\right)^{2}}{d^{2}}
$$

With $80 \%$ power using a cut off score for statistical significance of 0.05 and considering $10 \%$ follow up lost, the sample size was 70 (35 per group). The inclusion criteria were: age 40 and over, amenorrhea without any pathological reason, passing at least one year of the last menstruation, showing menopause symptoms, challenging with these symptoms and willing to take treatment. The exclusion criteria were: history of breast cancer and the use of tamoxifen, history of chemotherapy and malignant diseases, having active hepatic and renal diseases, use of androgen or progesterone, history of hormone replacement therapy, and taking any medications for treatment of menopausal symptoms.

The method of data collection was interview and questionnaires were used to collect data. The first part of the questionnaire was about demographic characteristics and menopausal information. The second part was about the severity of menopausal symptoms (Cooperman's index), based on the standard questionnaire with assessed reliability and validity $(16,17)$ used in Iranian studies $(13,14)$. To assess the validity of the questionnaire, content validity method was used; first, the questionnaire was translated, then it was sent to 10 specialists in the study field; finally, after gathering opinions and revisions it was used. To determine the questionnaire reliability, the test-retest method was used, in which 30 women answered the questionnaire when they referred for Pap smear test and it was repeated when they returned to receive their tests results (after four weeks). During this period, they did not take any medication. The correlation coefficient was calculated to be $82 \%$. The Cooperman's index was used to 
determine the severity of menopausal symptoms, including hot flushing, paresthesia, insomnia, nervousness, melancholia, vertigo, weakness, arthralgia and myalgia, headache, palpitation, and formication. Any of these symptoms gets a score between (0-3) based on asymptomatic $=0$, mild $=1$, moderate $=2$ or severe $=3$. Flushing gets a coefficient of 4 , paresthesia, insomnia and nervousness get a coefficient of 2 , and the rest of the symptoms get a coefficient of 1 . After calculation of scores and coefficients, the Cooperman's menopausal ind ex categories are obtained in four levels: asymptomatic (0-14), mild (15-20), moderate (21-35), and severe (more than 35) (18). Following a detailed description of the research procedures, written informed consents were signed by subjects. In addition, it was explained that their participation was voluntary and that they could leave the research at any moment without giving a reason.

Subjects were divided into two groups randomly using block randomization method. One group was treated with Vitagnus and the other with Calci soya balance. Both drugs were purchased from the market and put in encoded similar boxes. The person who prescribed the drugs was blinded to the types of drugs. After four weeks, Cooperman's questionnaire was completed by the subjects again. Then they received the second box of the drugs and four weeks later for the third time, completing the Cooperman's questionnaire was repeated. Among the participants, seven subjects were withdrawn from the treatment for causes such as gastrointestinal upsets (one subject of each group), allergies (one subject of the Vitagnus group), referring to a private clinic (two subjects of the Vitagnus group), not willing to continue taking drug without any reason (one subject of the Vitagnus group), and husband disagreement (one subject of the Calci soya balance group). Data were analyzed statistically using SPSS software version 11.5. Descriptive statistics (frequency, mean, standard deviation and median) and analytical statistics (chi-square test to compare qualitative variables, Mann-Whitney and Wilcoxon tests to compare quantitative variables) were used and the significance level ( $\alpha$ value) was selected to be 0.05 .

\section{Results}

After withdrawal of seven subjects, 30 women remained in the Vitagnus group and 33 women in the Calci soya balance group from the total of 70 women. Chi-square and Mann-Whitney tests did not show any significant difference between the two groups in terms of demographics, pregnancies, abortions, age and duration of menopause before intervention (Tables 1 and 2). Mann-Whitney test did not detect any significant difference between the Cooperman's menopausal index of the two groups before the treatment $(P=0.220)$.
Frequency of Cooperman's menopausal index categories in the two groups before taking the drugs was compared using chi-square test, and there was no significant difference between the two groups $(\mathrm{P}=0.902)$. In the Vitagnus group, median of Cooperman's menopausal index before the treatment was 25.5, while four weeks after the treatment it decreased to 19.0 and after eight weeks the median was 19.5. Wilcoxon test showed a significant decrease in mean of Cooperman's menopausal index before the treatment and after four weeks $(\mathrm{P}=0.000)$. In addition, Wilcoxon test detected a significant reduction of Cooperman's menopausal index after eight weeks, compared to before the treatment ( $P$ $=0.000$ ). Frequency of Cooperman's menopausal index categories in this group before taking the medication was compared to after four and eight weeks, using chisquare test (Table 3 ).

In the Calci soya balance group, the median of Cooperman's menopausal index before the treatment was 28.0, while four weeks after the treatment it decreased to 21.0 and after eight weeks, the median was 20.0. Wilcoxon test showed a significant decrease in the mean of Cooperman's menopausal index before the treatment and after four weeks $(\mathrm{P}=0.000)$. Furthermore, Wilcoxon test detected a significant reduction of Cooperman's menopausal index after eight weeks, compared to before the treatment $(P=0.000)$. Frequency of Cooperman's menopausal index categories in this group before taking the medication was compared with after four and eight weeks, using chi-square test (Table 3). Comparison of the means of Cooperman's menopausal index using Mann-Whitney test between the two groups before treatment showed no significant difference. In addition, comparison of these parameters after four and eight weeks of taking the drugs using MannWhitney test did not show any significant difference between the two groups (Table 4 ).

Table 1. Demographic Characteristics of the Two Groups Regarding Quantitative Variables ${ }^{\text {a }}$

\begin{tabular}{|c|c|c|c|}
\hline Variables & $\begin{array}{l}\text { Vitagnus } \\
\text { Group }\end{array}$ & $\begin{array}{l}\text { Calci Soya Bal- } \\
\text { ance Group }\end{array}$ & PValue $^{\mathrm{b}}$ \\
\hline Women's age, $y$ & $50.8 \pm 4.6$ & $51 \pm 4.7$ & 0.961 \\
\hline Husbands' age, y & $52.8 \pm 16.0$ & $55 \pm 11.8$ & 0.495 \\
\hline Pregnancies, No. & $3.5 \pm 1.4$ & $3.6 \pm 1.8$ & 0.646 \\
\hline Abortions, No. & $0.5 \pm 0.7$ & $0.7 \pm 0.8$ & 0.375 \\
\hline $\begin{array}{l}\text { Duration of meno- } \\
\text { pause }\end{array}$ & $2.7 \pm 2.3$ & $3.1 \pm 2.7$ & 0.696 \\
\hline Menopause age, $y$ & $48.1 \pm 3.4$ & $47.6 \pm 4.2$ & 0.771 \\
\hline
\end{tabular}

a Data are presented as Mean \pm SD.

b P values are related to Mann-Whitney tests. 
Golian Tehrani S et al.

\begin{tabular}{|c|c|c|c|}
\hline Variables & $\begin{array}{l}\text { Vitagnus } \\
\text { Group }\end{array}$ & $\begin{array}{l}\text { Calci Soya Bal- } \\
\text { ance Group }\end{array}$ & P Value ${ }^{\mathrm{b}}$ \\
\hline Marital status & & & 0.319 \\
\hline Married & $27(90)$ & $32(97)$ & \\
\hline Divorced & $2(3.3)$ & $0(0)$ & \\
\hline Widowed & $1(6.7)$ & $1(3)$ & \\
\hline Women's vocation & & & 0.479 \\
\hline Housewife & $27(90)$ & $27(81.8)$ & \\
\hline Employed & $3(10)$ & $6(18.2)$ & \\
\hline Husbands' vocation & & & 0.229 \\
\hline Jobless & $3(10)$ & $3(9.1)$ & \\
\hline Clerk & $3(10)$ & $4(12.1)$ & \\
\hline Self-employed & $15(50)$ & $13(39.4)$ & \\
\hline Retired & $9(30)$ & $13(39.4)$ & \\
\hline $\begin{array}{l}\text { Women's educational } \\
\text { level }\end{array}$ & & & 0.978 \\
\hline Illiterate & $2(6.7)$ & $2(6.1)$ & \\
\hline Elementary school & $8(26.7)$ & $9(27.3)$ & \\
\hline High school & $8(26.7)$ & $8(24.2)$ & \\
\hline Diploma & $9(30)$ & $11(33.3)$ & \\
\hline Associate & $2(6.7)$ & $1(3)$ & \\
\hline Bachelor and upper & $1(3.3)$ & $2(6.1)$ & \\
\hline $\begin{array}{l}\text { Husbands' educational } \\
\text { level }\end{array}$ & & & 0.276 \\
\hline Illiterate & $3(10)$ & $2(6.1)$ & \\
\hline Elementary school & $9(30)$ & $7(21.2)$ & \\
\hline High school & $8(26.7)$ & $6(18.2)$ & \\
\hline Diploma & $7(23.3)$ & $8(24.2)$ & \\
\hline Associate & $2(6.7)$ & $3(9.1)$ & \\
\hline Bachelor and upper & $1(3.3)$ & $7(21.2)$ & \\
\hline Socioeconomic status & & & 0.098 \\
\hline Low income & $3(10)$ & $2(6.1)$ & \\
\hline Average & $26(86.7)$ & $24(72.7)$ & \\
\hline High income & $1(3.3)$ & $7(21.2)$ & \\
\hline
\end{tabular}

\begin{tabular}{|c|c|c|c|c|c|c|}
\hline & \multicolumn{4}{|c|}{$\begin{array}{c}\text { Cooperman's } \\
\text { Menopausal Index } \\
\text { Categories }\end{array}$} & \multirow[t]{2}{*}{ Total } & \multirow[t]{2}{*}{ PValue $^{\mathrm{a}}$} \\
\hline & 莺. & 3 & $\begin{array}{l}3 \\
\frac{0}{0} \\
\frac{0}{20} \\
\frac{2}{2}\end{array}$ & $\frac{2}{3}$ & & \\
\hline \multicolumn{7}{|l|}{ Calci soya balance } \\
\hline $\begin{array}{l}\text { Before drug admin- } \\
\text { istration }\end{array}$ & 2 & 6 & 19 & 6 & 33 & \\
\hline After 4 weeks & 7 & 8 & 17 & 1 & 33 & 0.003 \\
\hline After 8 weeks & 8 & 9 & 15 & 1 & 33 & 0.009 \\
\hline \multicolumn{7}{|l|}{ Vitagnus } \\
\hline $\begin{array}{l}\text { Before drug admin- } \\
\text { istration }\end{array}$ & 3 & 5 & 18 & 4 & 30 & \\
\hline After 4 weeks & 8 & 9 & 12 & 1 & 30 & 0.006 \\
\hline After 8 weeks & 9 & 9 & 12 & 0 & 30 & 0.009 \\
\hline
\end{tabular}

${ }^{\mathrm{a}} \mathrm{P}$ values are related to Chi-square tests.
Table 4. Cooperman's Menopausal Index in the Two Groups Before and After the Drug Administration ${ }^{\mathrm{a}, \mathrm{b}}$

\begin{tabular}{|c|c|c|c|}
\hline Time & Vitagnus & $\begin{array}{l}\text { Calci Soya } \\
\text { Balance }\end{array}$ & P Value $^{\mathrm{C}}$ \\
\hline $\begin{array}{l}\text { Before drugad- } \\
\text { ministration }\end{array}$ & $25.50 \pm 7.82$ & $28.00 \pm 8.77$ & 0.220 \\
\hline After 4 weeks & $18.76 \pm 9.42$ & $19.93 \pm 8.53$ & 0.674 \\
\hline After 8 weeks & $17.36 \pm 8.69$ & $19.15 \pm 8.47$ & 0.482 \\
\hline
\end{tabular}

\section{Discussion}

In the present study, two groups of subjects were compared in terms of age, husbands' age, marital status, vocation of women and their husbands, educational level of women and their husbands, socioeconomic status, number of pregnancies, number of abortions, age at menopause, and duration of menopause. Chi-square and Mann-Whitney tests did not show any significant differences in any of the variables between the two groups. The two groups were compared before taking the medicine in terms of frequency of eleven menopausal symptoms (hot flushing, paresthesia, insomnia, nervousness, melancholia, vertigo, weakness, arthralgia and myalgia, headache, palpitation, and formication.) using chi-square test, and the difference was not significant in any case. In addition, chi-square test showed no significant difference between the frequencies of Cooperman's menopausal index categories of the two groups before taking the drugs. This implies a random distribution of subjects between the two groups and can help to interpret the results of the present study.

Due to the fact that going through menopause at the ages of less than 50 elongates the menopausal period, it is important to pay more attention to this natural period of women's lives, and discovery of a drug that can reduce annoying menopausal symptoms will help these women dramatically. The results of this experiment indicated that Vitagnus reduced menopausal symptoms, and our findings were similar to the Taghizadeh et al. (19), Kazemian et al. (14), and Chopin Lucks (20) studies. The intensity of menopausal symptoms significantly diminished after four weeks of treatment with Vitagnus, which may indicate that although Vitagnus is an herbal drug and it is expected to show its therapeutic effects after a long time, it could actually have beneficial effects in just four weeks, and this finding was similar to the results of the Kazemian et al. study (14). Meanwhile, there was also a significant difference in menopausal symptoms between four and eight weeks of taking Vitagnus, indicating that long term use of Vitagnus showed more positive effects, and thus, there was a similarity between the present experiment and Taghizadeh et al. study (19). However, in both 
experiments, most of the therapeutic effects appeared during the first month of the treatment. In the present study, the effects of Calci soya balance were also positive, which was similar to the findings of Ebrahimi and Yecta (13), Samiei and Sina (21), and Enjezab et al. (22); however, the results of some researches such as Bolanos et al. (15) and Levis et al. (23) were contrary to our findings, and they did not consider soya as an effective agent in reducing the bothersome menopausal symptoms. Comparison of the effects of Vitagnus and Calci soya balance on the frequency of Cooperman's menopausal symptoms index in four and eight weeks after taking the drugs did not show any significant difference between these drugs, indicating that they had equal effects in reducing the annoying menopausal symptoms after four and eight weeks. Therefore, Vitagnus as an herbal drug and Calci soya balance as a calcium and soya-containing supplement diminished the menopausal symptoms equally. Comparing individual menopausal symptoms between the two groups, only in the case of insomnia there was a significant difference between these medicines after four and eight weeks, but there were no significant differences between these medicines after four and eight weeks in any other symptoms. In the Calci soya balance group none of the subjects had severe insomnia, but in the Vitagnus group five women after four weeks and four women after eight weeks had drastic insomnia. In an experiment performed by Miehelle Bridenbacker on 60 postmenopausal women in 2002 , he reported that soya consumption lessened sleep disorders in half of the study population (24). On the contrary, another study performed by Balk and colleagues in 2002 announced that consumption of phytoestrogens such as soya increased sleep problems in postmenopausal women (25), whereas in the study of Samiei and Sina, it was reported that sleeping problems after soy consumption declined in all groups, especially the group that received $100 \mathrm{~g}$ of soya daily (21). It seems that metabolism of phytoestrogens varies between different people, which impacts the effectiveness of these compounds (26), so that phytoestrogens absorption has been estimated between $20 \%$ to $55 \%$ among different people (27). Regarding the beneficial effects of soya found in Calci soya balance, as well as helpful properties of the calcium in this supplement in preventing osteoporosis, it can reveal positive properties as much as Vitagnus in reducing annoying menopausal symptoms. Nevertheless, the results of the present study showed that both Vitagnus and Calci soya balance were effective in diminution of menopausal symptoms to a similar degree and the medical community can administer each of these two drugs based on patients' conditions and costs.

One of the strengths of this study was the use of doubleblind method. On the other hand, as our drugs had herbal bases, it would be better to have longer follow up durations to show the effects or side effects of our drugs in a more precise way. However, to achieve more definitive re- sults, the requirement of further investigations in larger populations and different societies is obviously felt.

\section{Acknowledgements}

The Research deputy of Tehran University of Medical Sciences and all the colleagues who helped us in advancing this project, especially Mrs. Badpar, are highly appreciated.

\section{Funding/Support}

This research was supported by Tehran University of Medical Sciences and Health Services, Grant number 9027-28-02-88; the registration ID in IRCT is IRCT201102215878N1.

\section{References}

1. Menopause. 2012. [updated 9 January 2014]; Available from: http://www.nlm.nih.gov/medlineplus/encyclopedia.html.

2. American Association for Clinical Chemistry. Menopause; 2010.

3. American College of Gastroenterology. Important Facts About Post Menopausal Hormone Replacement Therapy (HRT); 2010.

4. Berek JS. Berek and Novak's Gynecology. 14 ed philadelphia: Lippincott Williams \& Wilkins; 2007. pp.1323-8.

5. Fritz MA, Speroff L. Clinical Gynecologic Endocrinology and Infertility. 7 ed philadelphia: Lippincott; 2005. pp. 643-57.

6. Food and Drug Administration . [cited 7/2010]; Menopause and Hormones. 2009.

7. Han KK, Soares JM, Jr, Haidar MA, de Lima GR, Baracat EC. Benefits of soy isoflavone therapeutic regimen on menopausal symptoms. Obstet Gynecol. 2002;99(3):389-94.

8. Alternative Therapies: Phytoestrogens. Available from: http:/| www.menopausematters.co.uk/phytoestrogens.php.

9. Cathy Wong . Alternative Medicine. [cited January 12, 2011]; Available from: http://altmedicine.about.com.

10. Vitagnus. Available from: www.tebyan.net.

11. Shifren JL, Schiff I. Berek and Novak's Gynecology.philadelphia: Lippincott Williams \& Wilkins; 2007. pp. 1323-38.

12. Kim MK, Chung BC, Yu VY, Nam JH, Lee HC, Huh KB, et al. Relationships of urinary phyto-oestrogen excretion to BMD in postmenopausal women. Clin Endocrinol (Oxf). 2002;56(3):321-8.

13. Ebrahimi M, Yecta Z. Effect of Soya protein supplementation on menopausal symptoms. Hakim Res J. 2009;11(4):16-20.

14. Kazemian A, Bromandfar KH, Ghanadi A, Nourian K. Effect of Vitagnus and Passi-pay on hot flash of menopausal women. $J$ Shahrekord Univ Med Sci. 2005;7(1):39-45.

15. Bolanos R, Del Castillo A, Francia J. Soy isoflavones versus placebo in the treatment of climacteric vasomotor symptoms: systematic review and meta-analysis. Menopause. 2010;17(3):660-6.

16. Mascort C. Clínica e Investigación en Ginecología y Obstetricia 08. 2008;35(4).

17. Silva Filho CR, Baracat EC, Conterno Lde O, Haidar MA, Ferraz MB Climacteric symptoms and quality of life: validity of women's health questionnaire. Rev Saude Publica. 2005;39(3):333-9.

18. Alder E. The Blatt-Kupperman menopausal index: a critique. Maturitas. 1998;29(1):19-24.

19. Taghizadeh Z, Rezaipour A, Kazemnejad A, Mirsaeedi Z. The study of the effect of vitex agnus-castus on the early menopausal complications in menopaused women. Hayat. 2006;12(1):67-76.

20. Chopin Lucks B. Vitex agnus castus essential oil and menopausal balance: a research update [Complementary Therapies in Nursing and Midwifery 8 (2003) 148-154]. Complement Ther Nurs Midwifery. 2003;9(3):157-60.

21. Samiei H, Sina S. Comparison of the therapeutic effects of soybeans with HRT on menopausal syndrome manifestations. $J$ Babol Univ Med Sci. 2005;7(4):36-43.

22. Enjezab B, Mozaffari khosravi H, Khoshbin A, Faraj-Khoda T, Bokaee M. Effect of Soybeans on Hot Flashes in Postmenopausal 


\section{Golian Tehrani S et al.}

Women. J Shaheed Sadoughi Univ Med Sci. 2009;17(4):242-8.

23. Levis S, Strickman-Stein N, Ganjei-Azar P, Xu P, Doerge DR, Krischer J. Soy isoflavones in the prevention of menopausal bone loss and menopausal symptoms: a randomized, double-blind trial. Arch Intern Med. 2011;171(15):1363-9.

24. Natural soy lowers blood pressure in post menopausal women In: Miehelle Bridenbaker BS editor. 75th Scientific Sessisions of the American Heart Association 2002. 2002.

25. Balk JL, Whiteside DA, Naus G, DeFerrari E, Roberts JM. A pi- lot study of the effects of phytoestrogen supplementation on postmenopausal endometrium. J Soc Gynecol Investig. 2002;9(4):238-42.

26. Van Patten CL, Olivotto IA, Chambers GK, Gelmon KA, Hislop TG Templeton E, et al. Effect of soy phytoestrogens on hot flashes in postmenopausal women with breast cancer: a randomized controlled clinical trial. J Clin Oncol. 2002;20(6):1449-55.

27. Wolters M, Hahn A. [Soy isoflavones--a therapy for menopausal symptoms?]. Wien Med Wochenschr. 2004;154(13-14):334-41. 